\title{
Effectivity of Holothuria scabra and Spirulina platensis extract combination as an Antiinflammatory Agent Measured by Carrageenan-induced Rat Paw Edema
}

\author{
Renni Yuniati ${ }^{1 *}$ and Bambang Sulardiono ${ }^{2}$ \\ ${ }^{1}$ Dermatology and Venereology Department, Faculty of Medicine, Diponegoro University \\ ${ }^{2}$ Aquatic Resources Department, Fisheries and Marine Science Faculty, Diponegoro University \\ J. Prof. H. Soedarto, S.H., Tembalang, Semarang, Jawa Tengah, 50275 Indonesia \\ Email: renniyuniati@yahoo.com
}

\begin{abstract}
Sea cucumber, Holothuria scabra, can be found abundantly in Indonesian seas, which is also known to possess several medicinal properties. Spirulina platensis is another marine resources that has recently been extensively researched for its medicinal ability, such as anti-inflammatory effect. This study aims to evaluate the efficacy of $H$. scabra extract combined with S. platensis extract in reducing inflammation. This study uses male Wistar rats as the study animal. Inflammation was induced by injecting carrageenan solution into the mice paw. Combination of $H$. scabra and S. platensis extract with various combination ratio (1:1; 1:2; and 2:1) was applied to the mice paw. Diclofenac sodium was used as the standard control therapy. Edema inhibition rate and anti-inflammatory efficacy were measured by analyzing the edema size and calculating the edema difference. Combination of $\mathrm{H}$. scabra and S. platensis with 1:1 ratio has the largest edema inhibition volume compared to the other treatments. H. scabra and S. platensis combination outperforms the positive diclofenac sodium control group in terms of edema inhibition. The highest anti-inflammatory effect is obtained in the combination of H. scabra and S. platensis with 1:2 ratio, however, the anti-inflammatory efficacy is not as potent as the positive control. The effectivity of Holothuria scabra and Spirulina platensis extract in reducing the edema might be caused by their ability to reduce the levels of several inflammatory markers, including IL-6, NO, MMP9, and COX-2. This result suggests that $\mathrm{H}$. scabra and S. platensis combination has anti-inflammatory effect shown in mice paw edema model.
\end{abstract}

Keywords: sea cucumber; Spirulina, inflammation, diclofenac, edema inhibition rate

\section{Introduction}

Indonesia is known as one of the countries possessing extensive marine resources. Being located in the equator, with more than $78 \%$ areas comprised of shallow-water seas, Indonesia has a diverse amount of aquaculture species (Hutomo and Moosa, 2005; California Environmental Associates, 2018). Invertebrate species, such as shrimps, sea cucumbers and molluscs, can be harvested from seagrass meadows throughout Indonesia (Hutomo and Moosa, 2005). Indonesia is one of the biggest exporters of sea cucumbers, with more than 2 million $\mathrm{kg} . \mathrm{y}^{-1}$ from Indonesia, which has almost 10 million USD in value.

Sea cucumbers are mostly harvested and consumed because of their health benefits (Firdaus, 2019). In Asia, sea cucumbers has been consumed as food medicines and delicacies (Maziar Yahyav et al., 2012). Sea cucumbers are recognized as tonic and traditional remedy in Chinese and Malaysian literatures for its effectivity against various medical disorders (Bordbar et al., 2011).
Holothuria scabra, also known as teripang gosok or teripang pasir (sand sea cucumber), is one of the sea cucumbers harvested from Indonesian seas which has high economic values and are exploited commercially (Firdaus, 2019). This species is distributed in tropical waters of Africa, South China Sea, South Pacific, South-East Asia, and Indian Ocean (Bordbar et al., 2011). This species is usually exported as dried sea cucumbers to several countries in Asia, most notably China, Taiwan, Hongkong, Korea, and Singapore. In Indonesia, H. scabra is mostly sold as haisom (sea cucumber for cuisine purposes) (Firdaus, 2019).

H. scabra can be found in almost coastal areas, from shallow-water seas up to deeper seas in the coastal region. Dried sea cucumbers contain $82 \%$ protein, $1.7 \%$ fat, $8.9 \%$ water and $4.8 \%$ carbohydrate. Sea cucumbers also has several active ingredients, including triterpene glycosides (saponin), chondroitin sulphate, glycosaminoglycan, sterol, glucose sulphate triterpenes, sulphate polysaccharides, peptides, proteins (gelatin and collagens), hydrosalicylate, glycoproteins, lectin, phenols, and 
flavonoids (Arifin et al., 2013). The main saturated fatty acids contained in $\mathrm{H}$. scabra is palmitic acid, and the main unsaturated fatty acids contained in $H$. scabra is arachidonic acid (Yahyav et al., 2012).

The most important bioactive compounds contained in $\mathrm{H}$. scabra with experimentally confirmed pharmacological activity are triterpene glycosides (scabrasides B, D, echinoside A, 24dehydroechinoside A, HS-1, holothurins A, A1, A3, A4, B, B4, fuscocineroside C) (Khotimchenko, 2018). Nine triterpene glycosides, namely echinoside A, 24dehydroechinoside A, HS-1, holothurins B, B4, A and $A 1$, scabrasides $D$ and $B$, have been isolated from $H$. scabra. H. scabra also contains a variety of triterpene glycosides, including scabraside $D$, fuscocineroside $C$, and 24-dehydroechinoside A (Khotimchenko, 2018).

Several studies found that $H$. scabra has medicinal properties and benefits. $H$. scabra nhexane extracts has been shown to inhibit Escherichia coli bacterial growth (Arifin et al., 2013). Another study found that $H$. scabra extract has anticancer activity, which is shown by its ability to induce apoptosis against human glioblastoma cell lines. H. scabra triterpene glycosides has been shown to exhibit anti-proliferative activity and cytotoxicity against several tumor cell lines, including mouse leukemic cells (P-388), lung human cancer cell (A549), human colorectal cancer cell (HCT-116), gastric cancer cell (MKN28), and human breast cancer cell (MCF-7) (Khotimchenko, 2018).

Several sea cucumbers exhibit antiinflammatory activity. An in vivo study found that dried extracts of several species of holothurians $(H$. nobilis and $H$. axiologa) exhibits anti-inflammatory activity in rats against acute carrageenan-induced paw inflammation; however, its activity is lower than the synthetic standard compound (Aspirin) (Bordbar et al., 2011). H. polii has been shown to exhibit antiinflammatory activity decreases inflammatory markers (interleukin-6, interleukin-1 $\beta$, nitric oxide and matrix metalloproteinase 9) in mouse mammary SCp2 cells and THP-1 human monocytic cells (Kareh et al., 2018). As of our knowledge, Frodanol, extracted from the sea cucumber Cucumaria frondosa, is currently being the only patented antiinflammatory compound extracted from sea cucumbers (Kareh et al., 2018).

Spirulina platensis is a filamentous photoautotrophic green-blue algae that belongs to cyanobacteria (Suratno, 2010; Saranraj and Sivasakthi, 2014; Wollina et al., 2018). Spirulina is one of the edible cyanobacterias, along with some other species such as Nostoc and Aphanizomenon
(Saranraj and Sivasakthi, 2014). S. platensis is studied because of its high nutritional content which can be used in the medical field (Saranraj and Sivasakthi, 2014).

S. platensis is mostly composed of proteins around $50-70 \%$ of its dry weight. The essential amino acids contained in Spirulina includes leucine, valine, and isoleucine (Sotiroudis and Sotiroudis, 2013). Spirulina's green color comes from phycobiliproteins contained within Spirulina cells which serves as a light-collecting pigment for its photosynthesis activity. Phycobiliproteins consisted of three pigments: allophycocyanin, phycocyanin and phycoerythrin. From these three pigments, phycocyanin is the pigment that is mostly studied due to its potential benefits in the medicine field (Saranraj and Sivasakthi, 2014).

Several studies have found health benefits of S. platensis since they have antifungal activity against several fungi, including Aspergillus fumigatus, Mucor vulgaris, Penicillium expansum, Fusarium solani and Fusarium oxysporum; all of which contributes to the invasive mycoses infection (Otlu and Rudic, 2016). Spirulina is also found to be able to improve wound healing by increasing fibroblast proliferation and migration, enhanced wound closure rate, and inhibiting colonization of Staphylococcus aureus in wounds (Wollina et al., 2018). Anticancer activities can also be found in S. platensis. One research found that $S$. platensis has anti skin tumor effects in mice that is exposed to ultraviolet $B$ (UVB) rays (Yogianti et al., 2014).

S. platensis has also been found to exhibit antiinflammatory effect, as shown by several studies. One study found that $S$. platensis extract exerts antiinflammatory activity in diabetic rats (Nasirian et al., 2018). S. platensis has also been shown to decrease the inflammation as shown by the reduction of prostaglandin E2-induced paw edema in rats given 2 mg. $\mathrm{kg}^{-1}$ BW of S. platensis extract.(Somchit et al., 2014). Phycocyanin and $\beta$-carotene of Spirulina sp. might have important role in the anti-inflammatory effects (Wu et al., 2016). The blue pigment phycocyanin in $S$. platensis works as antiinflammatory agent, by acting as a selective inhibitor of the cyclooxygenase-2 (COX-2) enzyme, inhibiting the production of nitric oxide (NO) and prostaglandin E2.(Wollina et al., 2018). Besides that, phycocyanin is also able to inhibit the expression of TNF- $\alpha$, and IL- 6 which contributes to inflammation (Wu et al., 2016). This study aims to evaluate the effectivity of $H$. scabra and $S$. platensis combination in reducing inflammation, as shown by measuring edema size on carrageenan-induced inflammation in mice paw. 


\section{Materials and Methods}

H. scabra samples were harvested from Karimunjawa Islands, Indonesia by local fishers. The samples then were cleaned thoroughly with running filtered tap-water to prevent any residues of contaminants in the sea cucumbers itself. The whole sea cucumber body then were cut into small pieces (around $2 \mathrm{~cm}^{3}$ in size). The small pieces then were subjected to a second wash using filtered tap-water, to make sure that any contaminants that were hidden in crevices which were not expelled at the first washing are removed from the sea cucumber. The clean, small cuts of $H$. scabra then were blended with a $100 \mathrm{~mL}$ of demineralized water until a slurry is formed.

Two hundred grams of $H$. scabra blended sample were [it into a container filled with $400 \mathrm{~mL}$ of n-hexane. The mixture was soaked for 24 hours, and then were shaken for 5 hours at $150 \mathrm{rpm}$ shake rate.
This process was repeated three times until a clear filtrate is obtained. The filtrate was separated from the solids sediment using vacuum Büchner funnel. The solvent then was evaporated using rotary evaporator at $40^{\circ} \mathrm{C}$ temperature to obtain the crude extract. The crude extract was further processed using vacuum desiccator to obtain a thick extract.

The S. platensis algae used in this study were obtained from Karimunjawa Islands, Central Java, Indonesia. The raw S. platensis algae gathered from the Karimunjawa Sea were dried using oven drying method (heated for 7 hours in 80 degrees Celcius temperature using a laboratory-type oven) (Güroy et al., 2017) The dried S. platensis were crushed into fine powder. The powdered S. platensis microalgae was macerated in 95\% ethanol solution with 1:10 concentration (one part of S. platensis powder macerated in 10 parts of ethanol). The maceration process was done for 5 days in a glass container. The glass container was stirred every day to make sure

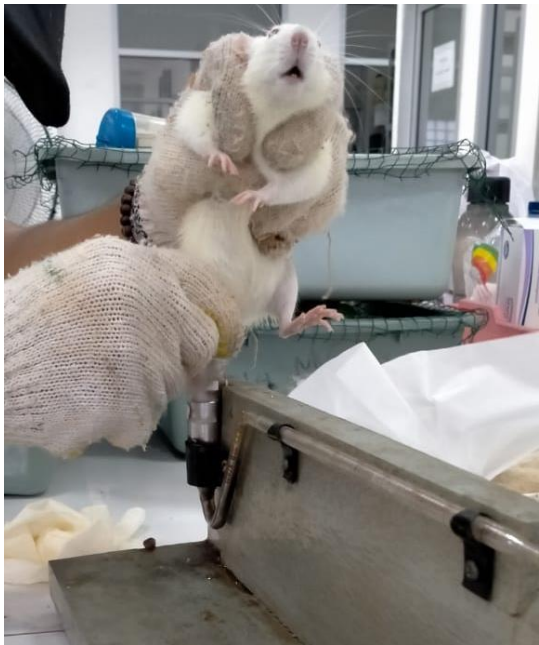

(a)

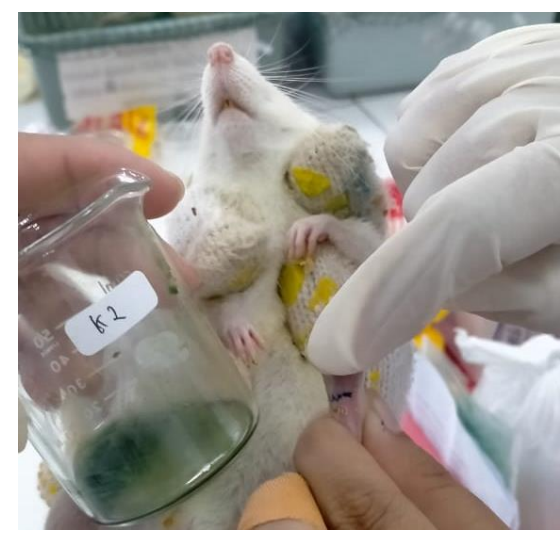

(c)

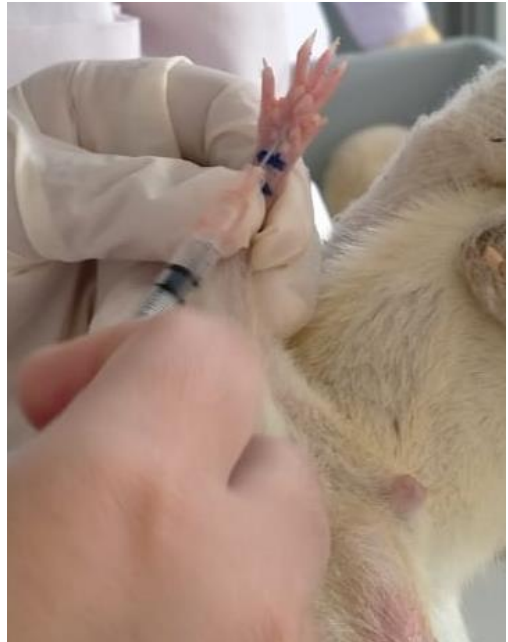

(b)

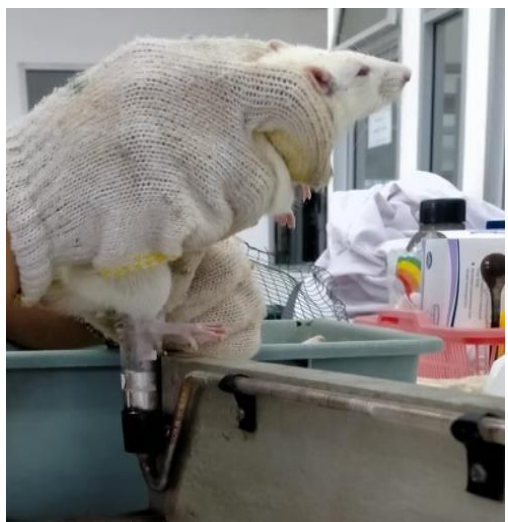

(d)

Figure 1. (a) Measurement of mice paw volume before carrageenan induction; (b) Induction of carrageenan into the mice paw; (c) Topical application of $H$. scabra : S. platensis mixturel (d) Measurement after one hour application of $H$. scabra : S. platensis mixture. 
the uniformity of the maceration process. The solution then was filtered through Whatman filter paper, and was evaporated using rotary evaporator machine at the ethanol boiling point temperature until a thick extract was obtained.

The anti-inflammatory activity of S. platensis and $H$. scabra was measured using carrageenaninduced rat paw edema assay. The subjects of this study were twenty-five Wistar male mice with a weight of $250 \pm 50 \mathrm{~g}$, which fulfilled the inclusion criteria for healthy conditions (active moves). The mice included in this study exhibited no signs that met our exclusion criteria, behavioral changes (activities seemed weak and lazy). Mice were kept at a constant room temperature of $28.0 \pm 2.0^{\circ} \mathrm{C}$ with fluorescent lighting that is turned on for 12 hours per day between 9.00 AM to 9.00 PM, with adequate food supply. The mice are obtained from a certified breeder with a purebreed lab mice certificate.

The preparation of rat paw edema assay begins with thorough cleaning by using water and bristles of rat paw to prevent any contaminates. Subplantar injection of $100 \mu \mathrm{L}$ freshly prepared $0,1 \%$ carrageenan in distilled water was injected in the right hind paws of each rat. Paw thickness before and after carrageenan injection (before any treatment was applied) were measured and noted.

The mice in group A were treated with $H$. scabra and S. platensis extract with 1:1. The mice in group B were treated with $H$. scabra and S. platensis extract with $2: 1$ ratio. The mice in group $C$ were treated with $H$. scabra and S. platensis extract with 1:2 ratio. We mixed the $H$. scabra and $S$. platensis extract according to the ratio for each group on separate containers. The positive control group were treated with one fingertip-unit (0.5 grams) of diclofenac sodium ointment as a standard therapy, and the negative control group were not treated (were only covered with dimethyl sulfoxide). All of the medications were applied topically in a thin layer to the mice paw. The edema volume and antiinflammatory efficacy were tabulated and analyzed statistically using computerized software.

This research has been ethically approved by Bioethics Commission, Medical Faculty of Universitas Islam Sultan Agung Semarang with the ethical clearance number of 172/V/2020/Komisi Bioetik.

\section{Results and Discussion}

For the average edema Mice given $H$. scabra : S. platensis with 1:1 ratio had the highest average edema inhibition volume among all study groups. The edema inhibition obtained in this group was even higher than the established medication (diclofenac sodium ointment). The positive control has almost similar edema inhibition volume as $H$. scabra : $S$. platensis with 1:2 ratio. This result shows that the topical application of $H$. scabra : S. platensis with 1:2 ratio has almost the similar efficacy as the established medication (diclofenac sodium ointment).

Mice given $H$. scabra : $S$. platensis with $2: 1$ ratio had lower edema inhibition rate compared to the two other therapeutic group and the positive control. However, statistical analysis shows that that there was no significant difference in results among the study groups (Table 1.).

The anti-inflammatory efficacy was measured by first calculating the increase of rat paw volume. The rat paw volume increase was measured by dividing the delta volume of rat paw before and after carrageenan induction by the initial volume. We measured the anti-inflammatory efficacy by dividing area under curve (AUC) between the negative control group and the therapeutic group. The AUC of the negative control group serves as the baseline value. Diclofenac sodium which is give at the positive control group had the highest anti-inflammatory efficacy, followed by topical application of $H$. scabra : S. platensis combination extract with 1:2 ratio. The other two remaining $H$. scabra : $S$. platensis extract combination achieved less than $20 \%$ of antiinflammatory efficacy. See Table 2.

The standard animal experimental model for testing anti-inflammatory drugs is by using carrageenan injection for inducing paw edema in rats (Amdekar et al., 2012) Carrageenan causes the release of proinflammatory and inflammatory mediators, hence causing inflammatory reactions at the rat paw which results in the formation of edema. There are two phases in carrageenan-induced edema; the first phase of edema is caused by the release of histamine, serotonins and kinins shortly after carrageenan injection, and the second phase of edema is caused by the release of prostaglandin-like substances after approximately two to three hours after carrageenan injection. Carrageenan was used as it is not antigenic and does not cause any apparent systemic effects. The use of carrageenan injection also allows a high degree of reproducibility (Amdekar et al., 2012; Solanki et al., 2015).

In this study, we found that Holothuria scabra and Spirulina platensis 1:1 combination yields in the largest edema inhibition rate. The average edema inhibition rate on the 1:1 group reaches $-0,108 \mathrm{~mm}^{3}$, which is larger than the other two combinations. This combination has better edema inhibition rate compared to $1: 2$ combination and 2:1 combination. 
ILMU KELAUTAN: Indonesian Journal of Marine Sciences September 2020 Vol 25(3):103-109

Table 1. Volume of edema in each study sample

\begin{tabular}{|c|c|c|c|c|c|}
\hline Grouping & $\begin{array}{l}\text { Initial Rat Paw } \\
\text { Volume }\end{array}$ & $\begin{array}{l}\text { Rat Paw Volume } \\
\text { after Caraagennan } \\
\text { injection }\end{array}$ & $\begin{array}{l}\text { Rat Paw Volume } \\
\text { after } 60 \text { mins } \\
\text { after application }\end{array}$ & $\begin{array}{l}\text { Edema } \\
\text { Inhibition } \\
\text { volume }\end{array}$ & $\begin{array}{l}\text { Average } \\
\text { edema } \\
\text { inhibition } \\
\text { volume }\end{array}$ \\
\hline \multirow{5}{*}{$\begin{array}{c}\text { H. scabra: S. platensis } \\
\text { extract } 1: 1\end{array}$} & 0,64 & 0,77 & 0,60 & 0,17 & \multirow{5}{*}{0,108} \\
\hline & 0,60 & 0,65 & 0,60 & 0,05 & \\
\hline & 0,72 & 0,84 & 0,70 & 0,14 & \\
\hline & 0,70 & 0,78 & 0,70 & 0,08 & \\
\hline & 0,60 & 0,70 & 0,60 & 0,10 & \\
\hline \multirow{5}{*}{$\begin{array}{c}\text { H. scabra: S. platensis } \\
\text { extract 2:1 }\end{array}$} & 0,52 & 0,54 & 0,54 & 0,00 & \multirow{5}{*}{0,048} \\
\hline & 0,55 & 0,62 & 0,58 & 0,04 & \\
\hline & 0,68 & 0,71 & 0,66 & 0,05 & \\
\hline & 0,56 & 0,66 & 0,60 & 0,06 & \\
\hline & 0,49 & 0,68 & 0,59 & 0,09 & \\
\hline \multirow{5}{*}{$\begin{array}{l}\text { H. scabra : S. platensis } \\
\text { extract } 1: 2\end{array}$} & 0,6 & 0,62 & 0,6 & 0,02 & \multirow{5}{*}{0,076} \\
\hline & 0,51 & 0,7 & 0,6 & 0,1 & \\
\hline & 0,3 & 0,55 & 0,4 & 0,15 & \\
\hline & 0,56 & 0,61 & 0,57 & 0,04 & \\
\hline & 0,54 & 0,62 & 0,55 & 0,07 & \\
\hline \multirow{5}{*}{$\begin{array}{l}\text { Positive control } \\
\text { (diclofenac sodium } \\
\text { ointment) }\end{array}$} & 0,58 & 0,73 & 0,60 & 0,13 & \multirow{5}{*}{0,070} \\
\hline & 0,46 & 0,65 & 0,58 & 0,07 & \\
\hline & 0,57 & 0,59 & 0,58 & 0,01 & \\
\hline & 0,54 & 0,66 & 0,61 & 0,05 & \\
\hline & 0,50 & 0,67 & 0,58 & 0,09 & \\
\hline \multirow{5}{*}{ Negative control } & 0,53 & 0,55 & 0,53 & 0,02 & \multirow{5}{*}{0,034} \\
\hline & 0,68 & 0,64 & 0,60 & 0,04 & \\
\hline & 0,49 & 0,58 & 0,55 & 0,03 & \\
\hline & 0,54 & 0,57 & 0,50 & 0,07 & \\
\hline & 0,43 & 0,46 & 0,45 & 0,01 & \\
\hline
\end{tabular}

Table 2. Anti-inflammatory efficacy of $H$. scabra and S. platensis.

\begin{tabular}{cccccc}
\hline Mice in each group & 1:1 ratio & $2: 1$ ratio & $1: 2$ ratio & Positive Control & Negative Control \\
\hline Mice 1 & 5,1 & 1,2 & 0,6 & 5,1 & 0,6 \\
Mice 2 & 0,9 & 3 & 8,4 & 9,3 & 3,6 \\
Mice 3 & 4,2 & 1,5 & 10,5 & 0,9 & 4,5 \\
Mice 4 & 2,4 & 4,2 & 1,8 & 5,7 & 2,1 \\
Mice 5 & 3 & 3 & 2,7 & 7,5 & 2,7 \\
\% Anti-inflammatory & $15,56 \%$ & $4,4 \%$ & $77,8 \%$ & $113,3 \%$ & $0 \%$ \\
\hline
\end{tabular}

The diclofenac positive control group has $0,07 \mathrm{~mm}^{3}$ edema volume inhibition. The interesting result is that the 2:1 extract combination yields in the lowest rat paw edema inhibition. This combination also has the lowest anti-inflammatory efficacy, only $4,4 \%$. Interestingly, the 1:1 extract ratio which has the highest edema inhibition level, only managed to reach $15.56 \%$ of anti-inflammatory efficacy, outnumbered by the $1: 2$ ratio.

The results of this study were similar to previous study conducted by Zuniarto et al. (2017). The authors compared the effectivity of $H$. scabra extract compared to Thrombophob ${ }^{\circledR}$ (heparin sodium) ointment on rat paw edema induced by carrageenan. The results of the study shows that lower concentration extract of $H$. scabra (15\% and
$30 \%$ extract) has better edema inhibition rate compared to heparin sodium ointment; whereas $60 \%$ $H$. scabra extract shows lower edema inhibition rate compared to heparin sodium ointment.(Zuniarto et al., 2017). On a different experimental model, Kareh et al. (2018) recently found that $H$. polii has antiproliferative and anti-inflammatory activity on human cultured cancer cells. In Indonesia, H. scabra is known as one of the sea cucumbers with high economical value. Various study has been done to identify bioactive compounds in sea cucumbers to further evaluate the potency of sea cucumber components.

The effect of $H$. scabra extract in reducing the inflammation might be attributed to the ability of $H$. scabra extract to reduce levels of Interleukin-6 (IL-6), 
nitric oxide (NO), and matrix metalloproteinase 9 (MMP9). However, the exact bioactive compound that contributes to this inflammation reduction were still under further research, due to the active substances identification difficulty.(Kareh et al., 2018).

The ability of $S$. platensis extract in reducing inflammation was attributed to several factors. Antiinflammatory agents produced by $S$. platensis are phycocyanin and $\beta$-carotene.(Wu et al., 2016). As an anti-inflammatory agent, phycocyanin contained in $\mathrm{S}$. platensis works a selective inhibitor of the cyclooxygenase-2 (COX-2) enzyme which is regulated during the inflammatory process and has the ability to induce apoptosis in macrophages. Other studies also concluded that phycocyanin was able to inhibit the expression of iNOS, COX-2, TNF- $\alpha$, and IL- 6 while $\beta$ carotene was able to inhibit the production of iNOS, COX-2, TNF- $\alpha$, and IL-1ß.(Wu et al., 2016; Sorg et al., 2017).

\section{Conclusion}

The combination of $H$. scabra : S. platensis extract with 1:2 ratio has the potential to be used as an anti-inflammatory agent with anti-inflammatory efficacy nearly similar to diclofenac sodium.

\section{References}

Amdekar, S., Roy, P., Singh, V., Kumar, A., Singh, R., \& Sharma, P. 2012. Anti-inflammatory activity of lactobacillus on carrageenan-induced paw edema in male wistar rats. Int. J. Inflammat., 17p. doi: 10.1155/2012/752015

Arifin, H.N., Ningsih, R., Fitrianingsih, A.A., \& Hakim, A. 2013. Antibacterial Activity Test Sea Cucumber Extract (Holothuria scabra) Sidayu Coast Gresik Using Disk Diffusion Method. Alchemy, 2(2):101-149. doi: 10.18860/al.v0i0.2882

Bordbar, S., Anwar, F., \& Saari, N. 2011. High-value components and bioactives from sea cucumbers for functional foods - A review. Mar. Drugs, 9(10):1761-1805). doi: 10.3390/md 9101761

California Environmental Associates. 2018. Trends in Marine Resources and Fisheries Management in Indonesia: A 2018 Review. 146. doi: 10.1109/RAMS.2010.5448016

Firdaus, M. 2019. Aspek Pembesaran Dalam Budidaya Teripang Pasir, Holothuria scabra. In Sugama (Ed.), Aspek Biologi Dan Budidaya Teripang Pasir Holothuria scabra (pp. 53-87). Kementrian Kelautan dan Perikanan, Badan
Riset dan Sumber Daya Manusia Kelautan dan Perikanan.

Güroy, B., Karadal, O., Mantoğlu, S., \& Irmak Cebeci, 0. 2017. Effects of different drying methods on C-phycocyanin content of Spirulina platensis powder. Ege J. Fish. Aqua. Sci., 34(2):129-132. doi: 10.12714/egejfas.2017.34.2.02

Hutomo, M., \& Moosa, M.K. 2005. Indonesian marine and coastal biodiversity: Present status. Indian Journal of Marine Sciences, 34(1):88-97.

Kareh, M., El Nahas, R., Al-Aaraj, L., Al-Ghadban, S., Naser Al Deen, N., Saliba, N., El-Sabban, M., \& Talhouk, R. 2018. Anti-proliferative and antiinflammatory activities of the sea cucumber Holothuria polii aqueous extract. SAGE Open Medicine, 6:205031211880954. doi: 10.11 $77 / 2050312118809541$

Khotimchenko, Y. 2018. Pharmacological potential of sea cucumbers. Int. J. Molecul. Sci., 19(5):1342. doi: 10.3390/ijms19051342

Yahyavi, M., Afkhami, M., Javadi, A., Ehsanpour, M., Khazaali, A. and Mokhlesi, A., 2012. Fatty acid composition in two sea cucumber species, Holothuria scabra and Holothuria leucospilata from Qeshm Island (Persian Gulf). Afr. J. Biotechnol., 11(12):2862-2668. doi: 10.58 97/ajb11.3529

Nasirian, F., Dadkhah, M., Moradi-kor, N., \& Obeidavi, Z. 2018. Effects of Spirulina platensis microalgae on antioxidant and antiinflammatory factors in diabetic rats. Diabetes Metab. Syndr. Obes.: Targets Ther, 11:375380. doi: 10.2147/DMSO.S172104

Otlu, I., \& Rudic, V. 2016. Antifungal activity of extracts from Arthrospira platensis against some pathogens, causing invasive mycoses. Curierul Medical, 59(6): 9-14.

Saranraj, P., \& Sivasakthi, S. 2014. Spirulina platensis - food for future: a review. Asian J. Pharm. Sci., 4(1):26-33.

Solanki, H.K., Shah, D.A., Maheriya, P.M., \& Patel, C.A. 2015. Evaluation of anti-inflammatory activity of probiotic on carrageenan-induced paw edema in Wistar rats. Int. J. Biolog. Macromol., 72:1277-1282. doi: 10.1016/j.ijbiomac.201 4.09.059

Somchit, M.N., Mohamed, N.A., Ahmad, Z., Zakaria, Z.A., Shamsuddin, L., Omar-Fauzee, M.S., \& Kadir, A.A. 2014. Anti-inflammatory and anti- 
pyretic properties of Spirulina platensis and Spirulina lonar: a comparative study. Pak. J. Pharm. Sci., 27(5):1277-1280.

Sorg, H., Tilkorn, D.J., Hager, S., Hauser, J., \& Mirastschijski, U. 2017. Skin Wound Healing: An Update on the Current Knowledge and Concepts. Eur. Surg. Res., 58(1-2), 81-94. doi: 10.1159/000454919

Sotiroudis, T., \& Sotiroudis, G. (2013). Health aspects of Spirulina (Arthrospira) microalga food supplement. J. Serb. Chem. Soc., 78(3):395405. doi: 10.2298/JSC121020152S

Suratno. 2010. Phytochemical Screening of Spirulina Platensis Microalgae Etanol Extract Which Has the Potential as an Antibacterial Agent. J. Surya Medika, 1(2):27-33.

Wollina, U., Voicu, C., Gianfaldoni, S., Lotti, T., França, K., \& Tchernev, G. 2018. Arthrospira Platensis Potential in Dermatology and Beyond. Open
Access Maced. J. Med. Sci., 6(1):176-180. doi: 10.3889/oamjms.2018.033

Wu, Q., Liu, L., Miron, A., Klímová, B., Wan, D., \& Kuča, K. 2016. The antioxidant, immunomodulatory, and anti-inflammatory activities of Spirulina: an overview. Arch. Toxicol., 90(8):1817-1840. doi: 10.1007/s00204-016-1744-5

Yogianti, F., Kunisada, M., Nakano, E., Ono, R., Sakumi, K., Oka, S., Nakabeppu, Y., \& Nishigori, C. 2014. Inhibitory Effects of Dietary Spirulina platensis on UVB-Induced Skin Inflammatory Responses and Carcinogenesis. J. Investig. Dermatol., 134(10):2610-2619. doi: 10.1038 /JID.2014.188

Zuniarto, A. A., Pradiningsih, A., \& Hamidah, A. 2017. Effectivity of Sand Teripang (Holothuria scabra) Ointment as an Antiinflammatory Agent Measured by Carrageenan-induced Rat Paw Edema. PharmaXplore, 2(3):94-103. 